\title{
A composição de imaginários assombrosos pelo sonoro único proposto nos filmes de animação de Fernando Cortizo
}

\author{
Helena Maria da Silva Santana \\ INET-MD, Portugal \\ Maria do Rosário da Silva Santana \\ Unidade de Investigação para o Desenvolvimento do Interior, Portugal
}

\begin{abstract}
In the analysis of the work of an author, we can see his evolution and development, not only at a technical and stylistic level, but also in the themes that define his being, his having, and his art. Through The Doll Thief, The Promise, The Cat Groomer and The Apostle of Fernando Cortizo we will analyze various work contents, in order to perceive in what way the music illustrates an imaginary, and how the use the stopmotion technique produces a discourse and a visual narrative, that will be used also by the composers Josh Rouse, Carlos Fernandez and Philip Glass in the structure of a sonorous that shows itself the author. It is our intention to perceive how the musical work is raised in order to elucidate these contents in the filmic proposals. We will look for facts and arguments that allow us to say whether the musical work, and the various elements that constitute it, are redefined in order to integrate better into the filmic contents, or if, on the other hand, they remain the same. We want to see if music emphasizing the image and builds another level of meaning, an alternative way of experiencing reality that, when not informed, appears cruel. In this set of films, filmmaker and other authors, draw a new look on human experience, allowing us a different reading of what is life, death, cruelty, sinister, ghostly. We want to understand how the different discursive plans compete there to clarify the works.
\end{abstract}

Keywords: Music for Film, The Thief of Dolls, The Promise, The Care of Cats, The Apostle, Fernando Cortizo

\section{Introdução}

Ao longo da história da produção de música para cinema notamos uma forte transformação nas bases que norteiam a função da música enquanto elemento construtivo e constitutivo da narrativa fílmica. O surgimento de tecnologias de produção, gravação, manipulação e transformação sonora revolucionou a forma como compositores e realizadores percebem, e interrogam, a função da componente sonora e musical no cinema. Enquanto os primeiros viram no cinema um meio de comunicação e produção capaz, os segundos perceberam que a natureza do sonoro e do musical poderia condicionar, senão manipular, a apreensão dos conteúdos visuais, emotivos, expressivos e dramáticos da componente visual da sua obra. A música como meio de determinação e concretização de uma narrativa, mas também como força medianeira na fixação das suas configurações emotivas e expressivas, foram estudados por numerosos autores ao longo da história, não só da música, como do cinema. Estes autores, de entre eles Claudia Gorbman (1987), Michel Chion (1990), Nikolas Cook (1998), Annabel Cohen (2001), Lipscomb e Tolchinsky (2005) ou Wingstedt (2016), confirmam a existência de diferentes formas de conceber e caracterizar musicalmente uma narrativa, narrativa essa que se mostra essencial para precisar e reforçar os diferentes meios, ações e intenções de realização de obra. No caso dos filmes de animação $O$ Ladrão de Bonecas (2005), A Promessa (2006), O Cuidador de Gatos (2008) e O Apóstolo (2010) de Fernando Cortizo, com música dos compositores Carlos Fernandez, Josh Rouse e Philip Glass, estas ações, e a utilização de universos sonoros e musicais, linguísticos e materiais, de características heterogéneas, permite, para além de uma eficaz ilustração e manipulação do visual, a construção de uma natureza outra ao nível do objeto de arte. Por outro lado, um som, o seu ideário, a sua expressividade e afetividade imanentes, permitem a construção de um outro estrato de significação às imagens construídas, e ao discurso fruído e expresso. Neste sentido podemos afirmar, à semelhança do que expõe Maheirie $(2003)^{1}$, que quando o sujeito está "mergulhado" numa música, ele significa o mundo à sua volta através da construção de diversas consciências afetivas. Nesta perspetiva, podemos afirmar que a música é uma linguagem reflexivo afetiva, já que envolve um tipo de reflexão que se faz possível por meio da afetividade, e uma afetividade que se faz possível por meio de determinado tipo de reflexão (Maheirie 2003). No nosso entender, este processo é determinante na construção da componente sonora de uma proposta fílmica.

Concomitante, a música pode assim ser compreendida como uma linguagem de reflexão afetiva. Ao escutarmos uma música podemos, por meio dela, tornar mais complexos os nossos saberes, definir melhor os nossos pensamentos, dar maior precisão às nossas posições, trazer para o presente um objeto que está ausente, e, até mesmo criar objetos imaginários. Para o ouvinte, uma música pode despertar novas reflexões, com ou sem a mediação de imagens (Maheirie 2003). No caso dos filmes em análise este processo revela-se bastante eficaz.

Para que se possa avaliar os processos de construção da componente musical e sonora de um filme é relevante conhecer como as suas caraterísticas extramusicais podem ser utilizadas; neste caso, as suas propriedades narrativas, componente muito explorada no desenvolvimento e criação de música para filme. No que concerne a construção de uma narrativa, de um discurso imagético e musical, a propriedade narrativa da música mostra-se quando ela, e o sonoro 
que evidencia, se mostram em narrações onde não se encontra um discurso exposto num diálogo de palavras, mas somente um discurso imagem, ou mesmo numa situação de ausência de imagens, ou discurso imagem (Blanco 2010). Burt (1994) ao falar sobre música para filmes, afirma que esta pode contribuir e auxiliar na caracterização das personagens, tanto individual como coletivamente, bem como das ideias e do ideário manifesto em filme. Pretendemos neste nosso trabalho, revelar a forma como a música evidencia os conteúdos da narrativa de Cortizo.

\section{Elementos de um imaginário na narrativa fílmica}

Na análise da obra de um autor, podemos perceber a sua evolução, não só a nível técnico e estilístico, mas também nos temas que lhe vão definindo o ser, o ter, e a arte. Neste nosso trabalho pretendemos, através da análise das curta-metragens $O$ Cuidador de Gatos, O Ladrão de Bonecas, A Promessa e $O$ Apóstolo de Fernando Cortizo perceber como é que a música ilustra um imaginário de autor. Pelo uso da técnica do stopmotion e o sonoro proposto por Josh Rouse, Carlos Fernandez e Philip Glass, veremos como estes autores interiorizam a proposta fílmica de Cortizo e, propõem um sonoro de autor consentâneo com a proposta fílmica. É nossa intenção perceber ainda de que forma a obra musical se constrói de modo a elucidar os conteúdos das propostas fílmicas, mas também o contrário. Neste sentido, buscaremos factos e argumentos para dizer se a obra musical e os diversos elementos que a constituem se redefinem para se integrar melhor nos conteúdos fílmicos, ou se, de forma contrária, permanecem os mesmos, sendo que é no visual, e pelo visual, que a obra adquire os conteúdos imagéticos da temática proposta.

De modo a conseguirmos realizar esta nossa intenção procederemos à análise e descrição das curtas-metragens de forma a conseguir definir o seu imaginário. Fernando Cortizo é um realizador que busca, através da imagem e do som, transmitir um universo de significações e significados de um dramatismo maior. Presentes nas imagens e nos sons, nos detalhes e na luz, assim como, nos indutores de ações e gestos, no drama e na visão do realizador, essas significações e significados surgem diversos nas propostas em análise. Analisando as obras, podemos afirmar que toda a narrativa se encontra repleta de imagens fortes que nos constroem imaginários não reais, mas que nos fazem refletir sobre a vida e a consciência humanas.

\subsection{O Cuidador de Gatos}

Em O Cuidador de Gatos, Fernando Cortizo apresenta-nos logo no início do filme uma imagem forte que anuncia a mensagem que quer transmitir. $O$ écran a negro, o som dos sinos da Catedral e o miar do gato, são três elementos fortes que nos cerram um imaginário que se mostrará presente em toda a proposta fílmica. A imagem da Catedral é um símbolo importante, pois propõe as temáticas do divino, da vida e da morte, do imaginário e do fantástico, presentes também no filme $O$ Apostolo. Entretanto surge a imagem de um homem que corre pelos telhados. Tal como os gatos que exploram os telhados em busca do que necessitam, na espreita constante à presa, do olhar na noite sob uma lua cheia e brilhante, o homem busca também ele o que necessita, a satisfação de uma sua necessidade. E, em grande plano, a sua imagem surge refletindo a sua marcha sobre os telhados. $\mathrm{E}$ o genérico imprime um outro ritmo, uma outra cor, dentro das que nos foram propostas na imagem da lua sobre o céu noturno de Cortizo.

Em outro, a imagem de uma panela, uma panela de onde se retira o alimento que está a ser distribuído num refeitório conduz-nos à imagem de dois homens que conversam sobre as suas funções. O discurso surge cortado por um écran negro e um relógio surge. Surge também a premonição de uma vida cíclica, constante e monótona, a vida que o ator principal leva em torno das suas satisfações básicas, mormente a alimentação e o recreio. E o relógio aparece mais uma vez, desta feita dando a hora certa, as 22 horas, a hora de saída para a rua, detendo-se a olhar uma borboleta que serpenteia na luz do candeeiro de rua, admirando a sua beleza. $E$ segue na sua missão que é alimentar os gatos, fonte, para ele, de uma enorme alegria. Neste ínterim a ação é interrompida pela visão de um outro personagem que assoma com uma lata de comida para os gatos, uma lata que se mostra mais atrativa para os animais. $\mathrm{E} o$ nosso personagem acorre para verificar o porque da fuga dos gatos em direção ao novo personagem. $E$ depara-se com uma lata de comida para gatos que irá alterar o curso de toda a narrativa.

$E$ volta o écran negro que nos leva a um retorno ao cenário da cantina e junto dos dois homens que servem comida no refeitório. E o homem que se encontra a varrer alerta o nosso personagem para o facto que este terá de cuidar mais da sua imagem e que se não o fizer será despedido, pois que não cumpre os requisitos exigidos para o lugar. $E$ sai para pesquisar sobre as latas de comida para gatos e encontra as latas. No conjunto dos desperdícios pega uma lata sendo esta a lata que o nosso protagonista leva para alimentar os gatos, atraindo os felinos com o novo objeto, os chama, e eles acorrem. Mas, mais uma vez o outro homem comparece tentando atrair os gatos, e o nosso herói o afasta correndo na sua direção e gritando que essa é a sua rua, o seu território.

Após uma interrupção, ouvimos a banda inicial do filme que ilustra uma outra fase da narrativa. E a perseguição se efetua e a imagem inicial surge, com o nosso herói correndo sobre os telhados. Neste fazer, surge novamente o écran negro cortando a ação. O nosso personagem se aproxima de uma luz e de uma porta aberta sobre um fundo azul e negro da noite. Cria-se o suspense e a tensão cresce. O personagem apresenta-se perante um cenário de máquinas que trabalham, num vai e vem, prenunciando morte. O sonoro intensifica a ação e as imagens que sugerem a morte e a transformação dos animais em comida que está sendo embalada e distribuída nas latas se anuncia. Incrédulo, o protagonista indaga. 
Infelizmente, as suas suspeitas se concretizam, pois que vê um funcionário da fábrica atirando um gato para a grande máquina trituradora. $E$ aparece o segundo personagem que alimenta os gatos e olha para a grande máquina, a intensidade dramática se acentua e o personagem é atirado, após confronto com o empregado, também ele para dentro da grande trituradora. As imagens sucedem-se, o silêncio instalase intensificando o poder dramático das imagens. A porta aberta convida a que se aproxime e veja o destino dos colegas e dos mendigos, a fábrica de comida para gatos. $E$ todos entram silenciosos no autocarro e as nossas suspeitas, bem como do protagonista se aclaram com a imagem publicitária da marca de comida para gatos "As Receitas da Avoa". Contudo, Mariano grita na tentativa desesperada de salvar o colega, pensamos nós, pela sequência das imagens e da narrativa. Mas, na sequência das imagens vemos que este se aproxima do autocarro para retirar um gato que se encontra debaixo das rodas do autocarro. $E$ o autocarro arranca após o olhar de reprovação do colega pela preocupação que Mariano tem com um simples gato. Nova imagem de écran negro surge e cuja sonorização é o arrancar e trabalhar de um motor a diesel, e o filme se termina, nas cores iniciais, com a imagem da avó e de "As Receitas da Avoa".

\subsection{O Ladrão de Bonecas}

O filme principia com a voz do narrador sobre fundo negro tal como em O Cuidador de Gatos. Da mesma forma, a primeira imagem é a de ruas vazias, na noite, em que uma lua cheia ilumina o cenário e o céu sobre fundo azul-escuro. Ponto importante, o início da história começa a ser contado com o écran negro e a lua cheia em todo o seu esplendor no centro do écran. As imagens das ruas desertas, com o candeeiro aceso que ilumina a escuridão, da mesma forma que a lua ilumina o caminho na noite, aparece. Esta imagem, surge, também ela comum, com O Cuidador de Gatos. Curiosamente, um gato aparece caminhando e atravessando toda a cena de forma calma e serena. Contudo, existe um momento de tensão, em frente a uma rua que nos dá a sensação de que algo se passa. É a imagem do velho que se encontra defronte a uma porta, o ladrão de bonecas. Nesta impressão, verificamos um outro ponto de contacto com o filme O Cuidador de Gatos: o miar do gato assustado, que anuncia a cena e imprime suspense. E a música surge ilustrando a imagem, numa melodia simples acompanhando o personagem qual leitmotiv. O écran escurece cortando o discurso e acicatando a nossa espectativa e, a imagem que, entretanto, se nos apresenta em tons de anil, convida à retrospeção e ao recolhimento, a reflexão e à espera. $E$ nesse momento de espectativa, surgem uns pés em grande plano que caminham tal como o gato. E o écran preto aparece novamente construindo um novo corte com a imagem da rua deserta iluminada pelo candeeiro trazendo a espectativa.

Ao não realizar qualquer ação, Cortizo descobre em nós a espectativa do devir e da ação, entrar e descobrir um mundo escondido por detrás de uma cena, por detrás de um grito, por detrás de uma porta, ou afastar-se como que se estivesse escondido e a resguardar-se do olhar do personagem que caminha apressado ao fundo como que a fugir do desconhecido. $E$ a imagem do écran negro reaparece. $E$ novamente a rua deserta, desta vez com dois candeeiros acesos ao mesmo nível, e o anúncio do que se nos vai ser apresentado no filme. Écran preto em flash e o nosso personagem assoma em grande plano olhando para nós de forma interrogativa, sendo que depois olha para cima e nos descobre uma janela iluminada numa casa dessa rua escura. A linha melódica no instrumento continua até que novo écran negro aparece e nos é anunciado o título do filme. Reaparece também a voz do narrador sobre écran negro que nos conta a história, uma história que se quer revelada. E a história inicia com a imagem do nosso herói no leito, tentando dormir. O candeeiro sobre a mesa-de-cabeceira faz a ponte com o candeeiro de rua. A mesma intensidade de luz, a mesma revelação, a mensagem e o enquadramento do cenário. E a história é contada num discurso sempre entrecortada pelas imagens negras. A história é-nos contada no silêncio, sendo que a idade adulta surge ilustrada com fundo de orquestra (cordas). Depois de contada a sua história de vida, e revelado o segredo das bonecas, reaparece a imagem da rua escura somente iluminada com um candeeiro. É-nos então revelada a essência de toda a história e do personagem - O Ladrão de Bonecas. É na noite, a coberto da escuridão, que o protagonista alcança o seu objetivo: arranjar bonecas para o seu estudo, resultado da revelação que teve aquando do longo processo de reflexão sobre a sua existência e o seu sofrimento em face da sua história de vida.

Da mesma forma que em O Cuidador de Gatos, neste filme o nosso personagem tem uma máquina trituradora de bonecas. A ação visa a obtenção de matéria-prima para a investigação. E a mudança no curso da história se dá, com o retorno à imagem da rua, desta feita com dois candeeiros em lados opostos do cenário, mudança esta corroborada pelo jogo de sinos que é o elemento sonoro presente. E o ladrão de bonecas se entrega ao seu trabalho com afinco, pondo em risco a liberdade, pois que se depara com o dono da casa que tenta assaltar no leito. Ouvem-se apitos da polícia na noite escura e um écran negro anunciando a tragédia se mostra. É a luta entre o bem e o mal, a inocência das bonecas e a maldade do homem, esta luta presente também na faixa sonora, agora dita no piano em ritmo acelerado, um ritmo construído em durações curtas e num andamento rápido ao nível da interpretação. E a cena da perseguição surge intensificada também pela presença do clarinete e das cordas, bem como do retorno à imagem da lua no centro do écran.

A junção de todos os elementos se dá, numa sobreposição em que se nota o cuidado em confrontar todos os elementos que anteriormente foram apresentados em sequência. E o sossego da rua deserta sob a luz da lua surge em contraste com a sonoridade do piano que denota a agitação própria da perseguição e da fuga. $\mathrm{O}$ som do gongo anuncia a mudança e o fim do discurso anterior, e a mudança 
se dá com o protagonista se dirigindo para a rua, exatamente no mesmo local onde o gato pára, olha e foge. Neste momento, vemos que ele carrega um saco vermelho às costas, o vermelho de um sangue que nos é induzido perceber na cena da máquina trituradora de bonecas. E o homem desaparece num cenário de ruas escuras parcamente iluminadas, num retorno discursivo e formal ao início da obra.

De novo o écran negro cortando o discurso, transportando-nos para o interior da habitação, onde o sonoro consiste no trabalhar incessante da máquina trituradora de bonecas. E a polícia bate à porta e o écran escurece mais uma vez. E o polícia abre a porta e atónito perscruta o interior da habitação. E toda a história nos é revelada na imagem que desponta do cientista, o doutor Hermes, detido pelo sequestro e assassinato de 143 meninas, para que encontrasse e extraísse, a partir delas, o elixir da juventude e da vida.

\subsection{A Promessa}

Tal como em O Cuidador de Gatos e em O Ladrão de Bonecas, Cortizo inicia a narrativa sobre écran negro com fundo galáctico suportado pelo sonoro. Um elemento de ficção científica, uma nave galáctica, surge ao centro do écran dando início a toda a narrativa, e a partir do qual se dá o bigbang inicial, a explosão revela o nome do filme - A Promessa, na voz do narrador (outra característica comum aos dois filmes já revelados). A nave galáctica surge em todo o seu esplendor e o nosso herói, o tripulante da nave galáctica, aparece desvelando o facto de ser o narrador da história. Da mesma forma é-nos revelado que desde que nasceu, existe uma promessa a cumprir, uma promessa confidenciada aquando da morte de sua mãe. A mesma voz que o alertou para o facto de o personagem ter que descansar, aparece agora para o alertar que existe uma mensagem do laboratório sobre a réplica. $E$ a imagem da nave galáctica no meio do universo na sua jornada contínua surge, imagem essa que se quebra com o retorno ao interior da nave quando o capitão se desloca ao laboratório e se depara com a sua réplica e, admirado, exclama que é uma réplica idêntica de si mesmo, um seu clone. E a morte do capitão se dá após pedido à réplica que nunca revele ao seu filho que é uma réplica dele mesmo. E o seu corpo desaparece no espaço pois que a imagem da nave galáctica no espaço sideral retoma a sua viagem sem fim. A nave arranca em direção à Terra que se encontra ao fundo. O écran escurece anunciando uma transformação importante. Esta acontece com o retorno à Terra e a cena que se apresenta, uma sala de espera onde o capitão surge e uma criança exclama papá, iluminando o rosto com um sorriso. E o écran escurece mais uma vez dando por terminada a narrativa, uma narrativa que se faz no conto de uma história onde o regresso do pai para o filho se dá sem que este dê conta que não é um clone do seu pai. Uma reflexão sobre a vida e a morte, sobre o significado da vida e das relações interpessoais, mas também da evolução da ciência e da necessidade do homem de se fazer eterno. Neste dizer confirmamos um paralelo com O Ladrão de
Bonecas. De uma ou outra forma o Homem procura a juventude e a vida eternas. De uma forma ou de outra, serve-se do conhecimento e dos meios que o cercam nessa busca, não aceitando o inevitável da morte e da transformação de uma matéria corpo.

\subsection{O Apóstolo}

Em O Apóstolo assistimos inicialmente à fuga de dois prisioneiros, Xavier e Ramon numa viagem em busca de um tesouro perdido numa aldeia do norte de Espanha. Esta aldeia vai-se revelar cheia de vivências de natureza não só material, mas, e sobretudo, imaterial, espiritual. Recém-fugido da prisão, Ramon vai à procura de um tesouro que foi escondido numa aldeia pequena e solitária, mas o que lá encontra é um ambiente sinistro que lhe mostra que a prisão onde se encontrava se mostrava bem mais amigável e desprovida de armadilhas que aquela pequena aldeia aparentemente pacata, calma e feliz. O ambiente sinistro, o mistério e o sobrenatural imperam não só nas formas, como nos espaços vivenciais das suas gentes. O mistério e o sobrenatural surgem nas falas e nas vivências de todos, sobretudo nas vivências do clero e daqueles que lhe são próximos. Entrados na aldeia, os fugitivos são alvo de diversas ações por parte da sua população. Não conseguindo fugir, verificam que o espaço se revela não um espaço de fuga, mas um espaço prisão. A aldeia, os seus habitantes e os modos de vida implícitos fazem com que esta se torne uma cadeia ainda mais terrível que aquela de onde tinham conseguido fugir.

Nela encontra anciãos sinistros, e acontecimentos estranhos como desaparecimentos de pessoas, para além de espíritos vários que atentam os habitantes, bem como um sacerdote que não segue os pressupostos de um religioso convencional. $\mathrm{Na}$ trama que se forma o nosso fugitivo cruza-se ainda com o Arcebispo de Santiago numa história de terror, humor e fantasia. As paisagens naturais, a recriação da Catedral Santiago de Compostela, e as expressões fantasmagóricas de alguns personagens induzem-nos para um clima marcado pela escuridão e pelo medo. $O$ nevoeiro do Caminho de Santiago abre espaço para a introdução do fantástico, a música e a natureza do sonoro enfatiza-o. Tecnicamente O Apóstolo surge uma obra de inegável valor artístico, encontrando-se delineado, numa inflexão gótica, que nos remete para alguns trabalhos de Tim Burton. Realçamos ainda o arrojo do cineasta em ser fiel a diversas lendas galegas construindo um filme de animação destinado a adultos. Destacamos identicamente a banda sonora da autoria de Philip Glass, que claramente dá densidade e dramatismo ao ambiente criado.

Para além de música composta por Philip Glass, o filme encontra-se ilustrado com excertos de música da autoria de Xavier Font ${ }^{2}$ e Aturo Vaquero ${ }^{3}$, incluindo ainda alguns excertos de música popular espanhola. $\mathrm{O}$ uso de diferentes efeitos sonoros que elucidam de forma viva e continuada a narrativa do filme é uma constante, sendo que os sons são aqueles que melhor ilustram não só os objetos, como as personagens, as situações, as vivências, as emoções e a narrativa 
fílmica, construindo o terror, o suspense e a emoção contínuos. O uso da orquestra e das vozes de forma predominantemente homofónica e homorritmica favorece a característica minimalista da música do filme quando da autoria de Philip Glass. Notamos que a construção por repetição continuada dos mesmos motivos é uma constante no autor revelando-se delineadora de um estilo que se mostra uniforme na sua obra. A mestria da orquestração permite que a natureza e a particularidade dos timbres e da sua combinatória se revistam de uma aura que enobrece e clarifica os conteúdos imagéticos da narrativa, do texto, dos diálogos, das personagens, das emoções e dos sentimentos.

O uso de sons da natureza próprios do ambiente das cenas que se mostram e sequenciam determina uma forma de caracterizar esses mesmos ambientes contribuindo para a natureza, por vezes fantasmagórica e alegórica dos sons, das imagens e dos contextos expressos. Embora, e na opinião de alguns críticos, as expectativas face ao filme de alguma forma saem logradas, o produto final deste filme de animação revela uma forma inabitual de contemplarmos o filme de animação para um público adulto. Revela ainda, e no nosso entender, um nível de inteligência e perspicácia elevados ${ }^{4}$. A música, enfatizando a imagem, constróiIhe um outro nível de significação.

Após a descrição realizada, denotamos que neste conjunto de filmes, cineasta e demais autores, desenham um seu olhar sobre a vivência humana, permitindo uma leitura diferenciada do que pode ser a vida, a morte, a crueldade, o sinistro, o fantasmagórico, o material e o espiritual desenhado em arte. É nossa intenção perceber a forma como os diferentes planos discursivos aí concorrem para a sua clarificação. Tentaremos agora perceber de que forma os universos criativos de Fernando Cortizo se mostram nas propostas dos compositores que o mesmo elege para se mostrar som, imagem, discurso e arte.

Quando ao homem foi possível, através do uso de tecnologia de sincronização de som e imagem, definir um modelo de produção/exibição fílmica diferenciada, estava ameaçada a supremacia da imagem pura, e do filme mudo, em particular. Mas quando falamos de sonoro e de musical, falamos não só do uso de elementos sonoros provenientes do uso puro dos som-palavra e dos som-discurso/ diálogo, elementos possuidores de uma significação e significado provenientes dos conteúdos imagéticos, emotivos e expressivos neles descritos, manifestos e apreendidos, como do uso dos som-ruído e/ou de elementos e texturas musicais mais elaborados. Mas nem todos os teóricos advogam a importância do uso do discurso sonoro na construção do objeto fílmico ${ }^{5}$. Deste facto se infere que estes elementos não possuem a relevância necessária para que os considerem objeto de estudo e reflexão. Considerados como uma mera cópia da realidade, os sons-ruído foram, a par dos som-discurso/diálogo, considerados elementos indesejáveis na produção da nova arte, sendo relegados, quando utilizados, para segundo ou terceiro plano ${ }^{6}$. O uso de fragmentos musicais foi aceite enquanto necessidade atávica do novo meio de produção artística que, fruto de uma novidade, ainda não possuía meios conceptuais e expressivos reveladores de um pensamento capaz, manifestando, por isso, uma duvidosa qualidade musical e expressiva. Todavia, o desenvolvimento da nova arte faz-se obrigatoriamente na introdução do elemento sonoro, elemento este que se encontra presente não só ao nível do discurso falado, elementos sompalavra e som-discurso/diálogo; como ao nível de um discurso sonoro constituído de elementos som-ruído e de elementos ou texturas musicais mais elaborados (como fragmentos de obras musicais). Se a utilização de um novo discurso coloca questões no que respeita a sua conceção, conceptualização e formalização, o processo criativo encerra em si, não só exigências de carácter mais geral, como outras, de carácter mais específico (as de cada autor), que naturalmente surgiram como agentes de metamorfose imagéticomusical. Simultaneamente, a produção de um objeto conjunto, entre realizador e compositor, implica uma interação entre os autores que se traduz numa obra comum que respeite uma e outra subjetividade.

Mas se aceitarmos que a componente musical concorre para a construção do objeto fílmico, muitos são os autores que entendem que o discurso musical não se deve sobrepor ao discurso da narrativa e ao discurso das imagens. A componente musical não deve, segundo eles, dispersar-se da temática da história nem sobressair em caso algum sobre os discursos manifestos. Este facto permite que não se origine um desequilíbrio, se não distorção, da linha dramática vivida. Neste sentido, Münsterberg (in Langdale 2002) propõe a música como elemento destituído de um caráter representativo. Neste caso, não seria ela uma impureza na linguagem das imagens e também um recurso que aproxima o cinema do teatro? Não seria admitir que o cinema, mais do que autorizar a participação de um discurso sonoro ou musical, depende deste para captar de forma mais eficaz a atenção do espectador? Qual seria o grau de autonomia e pureza de uma arte que necessita do apoio de um outro meio de expressão para captar a atenção dos seus espectadores? Se a componente musical se revela imprescindível na construção do objeto cinematográfico, como poderia não ser considerada fundamental? E como se processaria a construção de imaginários e imagéticas sonoras numa afetividade sempre presente, e consequentemente imanente, daquilo que se mostra som e arte?

\section{A música na narrativa fílmica}

No campo das teorias gerais não podemos deixar de referir, no contexto deste trabalho, Sigfried Kracauer (1997), o primeiro a apresentar uma proposta de classificação das funções da música no cinema. Para ele a música divide-se entre música de acompanhamento, música real e música como núcleo do filme. Kracauer (1997) designa as funções da música por acompanhar, reafirmar, sublinhar, ilustrar ou duplicar a imagem. Maurice Jaubert, e em muitos 
aspetos de forma diversa, realça alguns aspetos que para ele devem estar presentes na determinação e construção de uma música para cinema. Para ele: a) a música não deve preencher vazios; b) a música não deve comentar a ação; c) a música não deve ocorrer ao mesmo tempo que as vozes ou os sons diegéticos; d) revela-se despropositado considerar a música dramática e expressiva na sua essência expressiva; e) a música não deve conter elementos subjetivos, deve ser tão realista quanto a imagem e dar-nos evidência física do seu ritmo sem se limitar a uma tradução de conteúdos (Chion 1990). Este autor entende ainda que a música deve salientar o ritmo da imagem sem se tornar uma tradução servil do seu conteúdo (seja ele emocional, dramático ou poético). Simultaneamente, e uma vez libertada dos seus compromissos académicos, a música revelará, para ele e através do filme, um aspeto de si mesma até então incogitável (Chion 1990).

Sabendo que, os todos os criadores pretendem, mesmo que o não admitam, estimular respostas afetivas nos seus espectadores através de uma construção cuidada da componente musical da obra de arte, questionamo-nos se será possível identificar e catalogar algumas das técnicas e intenções mais utilizadas na construção da narratividade musical, nas propostas apresentadas - no caso os filmes O Ladrão de Bonecas, O Cuidador de Gatos, Promessa e O Apóstolo de Fernando Cortizo. Tentando responder a estas questões debruçamos a nossa atenção sobre o uso da componente sonora e musical na delineação de conteúdos emotivos, expressivos, dramáticos e visuais relativo aos objetos: voz/som-palavra, efeito sonoro/som-ruído, elemento musical/ peça musical.

\subsection{Análise}

Debruçamos agora a nossa atenção sobre os quatro filmes de animação da autoria de Fernando Cortizo O Ladrão de Bonecas ${ }^{7}$, A Promessa ${ }^{8}$, O Cuidador de Gatos $^{9}$ e $O$ Apóstolo ${ }^{10}$ - com propostas musicais dos compositores Josh Rouse, Carlos Fernandez e Philip Glass. As propostas que nos propomos analisar constituem-se em quatro filmes de animação, realizados utilizando a técnica stop-motion. Neste fazer revelam uma forma inabitual de contemplarmos um produto tão singular como é o caso o filme de animação. De salientar que todas as propostas se dirigem a um público adulto, revelando, no nosso entender, um nível de inteligência e perspicácia elevados. O stop-motion, sendo uma técnica de animação que se determina fotograma a fotograma (ou quadro a quadro), utilizando como recursos materiais para a sua captação tanto uma máquina de filmar, como uma máquina fotográfica ou mesmo um computador, permite um manuseamento dos materiais, uma reflexão sobre o ato criativo e sobre os elementos entretanto produzidos e materializados arte, mais efetiva, refletida e eficaz. No nosso entender, o processo de manipulação física do material que dá forma aos cenários, aos personagens e a tudo o que envolve a materialidade do filme, permite aos seus autores uma maior vivência física desses mesmos materiais e realidades projetadas ser e arte ${ }^{11}$.

\section{Voz/som-palavra}

No que concerne a Voz/som-palavra, salientamos a sua utilização nos filmes $O$ Ladrão de Bonecas, O Cuidador de Gatos, A Promessa e O Apóstolo de Fernando Cortizo. Neste caso, verificamos o uso de padrões recorrentes constituídos por elementos sonoros com uma carga emotiva e expressiva próprias. A voz, pela sua natureza física e expressiva, constrói um imaginário que, quando bem manipulado, consegue efeitos dramáticos e emotivos no espectador difíceis de conseguir por outros meios sonoros $^{12}$. A escolha de um ator, ou narrador, em função do tipo de voz que apresenta realçando assim os conteúdos emotivos e dramáticos veiculados pelo filme, não se faz ao acaso, ela é fruto da afirmação de uma vontade que tem origem num processo cognitivo de perceção da espécie humana e que, se queremos enfatizar, podemos utilizar. Em Fernando Cortizo este facto revela-se avassalador. Contudo, a voz surge igualmente interligada com o diálogo e a função de narrador. Neste caso é particularmente importante a escolha de um timbre apelativo, e eficaz, para que o veicular de um conjunto de características associadas a uma boa representação das emoções e dramatizações das ideias e do ideário contido na narrativa se faça, e que nos filmes em análise surgem misteriosas, senão macabras.

\section{Efeito sonoro/som-ruído}

O uso de diferentes efeitos sonoros oferece condições ótimas para a manipulação emocional do fruidor de um discurso fílmico. Respostas emotivas são obtidas através do uso de uma diversidade de técnicas e recursos onde podemos incluir: a audição de ruídos vários ( $O$ Ladrão de Bonecas, O Cuidador de Gatos, $A$ Promessa e O Apóstolo); o som/ruído como leitmotiv (O Ladrão de Bonecas); a deslocação espacial de sons (musicais e/ou não-musicais) enfatizando as suas principais características (não só objetivas, como subjetivas; em exemplo o gato em O Ladrão de Bonecas, mas também em O Cuidador de Gatos); a interrupção momentânea e/ou abrupta da componente musical (O Apóstolo); o surgimento inesperado dessa componente (O Ladrão de Bonecas, O Cuidador de Gatos, A Promessa e O Apóstolo); o retardamento do processo de identificação da fonte sonora, etc. (Browrigg 2003). No último exemplo encontramos os sons de portas rangendo, janelas batendo, grunhidos de animais, gritos, etc., procurando sempre a criação de tensão e suspense.

O uso de efeitos sonoros tais que: crescendos; decrescendos; glissandos; aumento ou diminuição brusca da intensidade (dinâmica); consonâncias; dissonâncias; acelerandos e ritardandos, etc., permitem não só sublinhar, como reafirmar, ilustrar ou duplicar conteúdos (presente nas quatro propostas em análise). No crescendo, como o nome indica, o compositor promove um aumento progressivo da intensidade geral da textura musical; no decrescendo, o inverso (O Cuidador de Gatos).

Se o uso da consonância é concordante quanto ao efeito que produz em quem a frui, o uso da dissonância 
propícia a caracterização de atmosferas cujas emoções caracterizantes são predominantemente o desequilíbrio, a incompletude, a instabilidade, a estranheza ( $O$ Ladrão de Bonecas; $A$ Promessa) ${ }^{13}$. O tipo de instrumentação e orquestração revelam-se primordiais na caracterização do discurso fílmico (O Ladrão de Bonecas; O Cuidador de Gatos; A Promessa; O Apóstolo). No entanto queremos salientar que por si só a caracterização timbrica de uma textura musical não é suficiente para transmitir uma emoção, um sentimento. A música é uma estrutura global onde melodia, ritmo, harmonia, timbre, dinâmica, fraseado, forma de ataque, textura, densidade, entre outros, concorrem para a determinação do elemento musical potenciando o emergir de um sentimento, de uma emoção, específicos, como podemos constatar nos objetos posteriormente analisados. Por outro lado, a sua estética e estilo, são potenciadores de uma ação fruitiva distintas.

\section{Elemento musical/peça musical}

O uso de elementos musicais mais elaborados, nomeadamente pequenas peças ou fragmentos de peças musicais, tem como objetivo e função, aqueles já descritos (O Ladrão de Bonecas, O Cuidador de Gatos, Promessa, O Apóstolo). O género musical, a forma da obra, a determinação métrica e temporal da peça construída, a instrumentação e orquestração, bem como os meios, tradicionais ou outros, convocados à sua realização, são consequência direta dos objetivos dos seus criadores enquanto construtores de imaginários comuns, manipuladores de vontades, agentes de arte. Estes factos tornam-se evidentes nos quatro filmes em análise, sendo preponderantes na forma como descrevem e caracterizam as personagens e as narrativas propostas. Neste caso salientamos o uso de elementos que se constituem até como Leitmotiv em O Ladrão de Bonecas, bem como em $\mathrm{O}$ Cuidador de Gatos. A diferença de género musical contribui igualmente para o enfatizar dos conteúdos da narrativa.

\section{Conclusão}

No processo de análise das obras $O$ Ladrão de Bonecas, A Promessa, O Cuidador de Gatos e O Apóstolo de Fernando Cortizo notamos que a componente sonora realça não só determinados momentos da narrativa, como caracteriza personagens, revela pensamentos e sentimentos, distingue intenções, valores e ideários, tanto dos seus atores e autores, como dos seus fruídores e intérpretes. A componente musical surge ainda com o intuito de introduzir o ambiente emocional da história narrada e vivida, preparando o espectador para os acontecimentos que irão suceder. Neste sentido observamos que a componente sonora nas quatro propostas em análise se revela delineadora, senão clarificadora, dos conteúdos imagéticos, expressivos, dramáticos e emocionais da obra vivificada.

É ainda de considerar que a música, e a criação artística contemporânea obrigam o ser humano a confrontar-se consigo próprio, e com o mundo exterior a si, levando-o ainda a autodefinir-se através de uma constante pesquisa das estruturas discursivas e estéticas do objeto de arte e daquilo que nele se diz. Assim, a descoberta do filme e de si, do som e da arte, dos instrumentos, códigos e modelos operantes e deformantes de um modo cristalizante e cristalizado de ser homem, humano e arte, conduzem o individuo na descoberta do interior de si, servindo-se do exterior a si; o som e a narrativa fílmica, sistemas operantes e determinantes de novas formas de ser e interagir consigo, com o mundo, o real e a arte.

Os filmes revelam um ser face a um conjunto de realidades, nomeadamente a busca do elixir da felicidade (muitas vezes o elixir da juventude; $O$ Ladrão de Bonecas), a morte e a necessidade de cumprir com as promessas feitas (A Promessa), a solidão e a inadaptação social e afetiva ( $O$ Cuidador de Gatos), a continuidade da vida que nos dias de hoje desperta a necessidade de permanecer para além da morte através da clonagem (A Promessa), o contato com o mundo espiritual, assim como a manifestação de diversas temáticas de ordem filosófica, mística, religiosa e espiritual através da arte (O Apóstolo), realidades que se percutem desde sempre. Estas realidades, bem como os imaginários daí decorrentes, são transpostos de forma magistral na forma como os criadores, compositores e cineasta, concebem a obra de arte musical, e o filme em particular. A música enfatizando a imagem constrói-lhe um outro nível de significação, bem como uma outra forma de vivenciar a realidade que, quando não informada, surge plena de temor, terror, senão crueldade. Neste conjunto de filmes, da autoria de Fernando Cortizo, tanto o cineasta como os demais autores, desenham um novo olhar sobre realidades bem importantes da vivência humana: a vida, a morte, os espíritos, a crueldade, o sinistro, o fantasmagórico, quiçá, um espelho do humano.

\section{Notas Finais}

${ }^{1}$ Autor que também associa a música com a afetividade.

${ }^{2}$ Xavier Font é um compositor catalão que reside em Santiago de Compostela. A sua formação musical passa pelo estudo do Piano e da Guitarra e por um aprofundamento autodidata da sua formação musical. Através do seu trabalho alcançou diversos prémios. Enquanto compositor de música para filmes colabora com diversos compositores, nomeadamente Arturo Vaquero e Philip Glass. Da sua obra para filme destacamos Abrígate (2007) e Ma morta (2008, sob a direção de Ramón Costafreda), Cartas Italianas (2007) e Relatos (2009, sob a direção de Mario Iglesias), Agallas sob a direção de Samuel Martín e Andrés Luque, El diario de Carlota (2010, sob a direção de José Manuel Carrasco) e O Apóstolo (2010, sob a direção de Fernando Cortizo).

${ }^{3}$ Arturo Vaquero nasceu em Santurce, Vizcaya, Espanha, em 1971. É conhecido pelo seu trabalho em O Diário de Carlota ou O Apóstolo já mencionados.

${ }^{4}$ Stop-motion é uma técnica de animação fotograma a fotograma (ou quadro a quadro), que utiliza como recurso tanto uma máquina de filmar, como uma máquina fotográfica ou um computador. Na realização destas animações são produzidos e utilizados modelos reais em diversos materiais, sendo os mais comuns a massa de modelar ou plasticina. Conforme a técnica e a necessidade que se manifeste, muitos contêm sistema de juntas mecânico, com mecanismos de articulações muito 
complexos e reais. No caso de realização de filmes que não a curta-metragem, o material utilizado tem de ser mais resistente e maleável. Os modelos são movimentados e fotografados quadro a quadro. Esses quadros são posteriormente montados numa película cinematográfica, criando a impressão de movimento. Nessa fase, podem ser acrescentados efeitos sonoros, como fala ou música. Tim Burton é um dos mais profícuos realizadores de filmes com a técnica Stop Motion. Um dos muitos filmes que produziu utilizando esta técnica foi O Estranho Mundo de Jack (1993, sob a direção de Henry Selick). Outros exemplos comportam A Fuga das Galinhas, Wallace e Gromit, Coraline e O Mundo Secreto e O Fantástico Sr. Raposo (2009, sob a direção de Wes Anderson), além de A Festa do Monstro Maluco (1967) ou A Noiva Cadáver e Frankenweenie (2012).

5 No que se refere ao uso dos som-palavra, sabemos que os repelem de forma vigorosa (não da palavra enquanto som-ruído). Quanto ao uso do som-ruído, notamos que o seu emprego se encontra limitado a um número mínimo de opções sonoras (efeitos).

6 Para os formalistas o emprego naturalista do som sincronizado era uma degradação que levaria o cinema à condição de teatro filmado. Esta ação, ameaçando a integridade da sua pureza, enfraqueceria a relevância e poder artísticos da imagem. Na opinião de Hugo Münsterberg, os ruídos não têm o direito a existir numa obra de arte que é composta por imagens. (Münsterberg in Langdale 2002). Outros autores, possuem outro entendimento sobre a sua utilização em cinema e em arte.

${ }^{7} \mathrm{Em} O \mathrm{~L}$ adrão de Bonecas, filme de animação realizado sob a direção de Fernando Cortizo em 2005, a parte musical surge composta pelo compositor espanhol Carlos Fernandez.

${ }^{8} \mathrm{Em}$ A Promessa, filme de animação realizado sob a direção de Fernando Cortizo em 2006, a parte musical é da autoria do compositor Carlos Fernandez.

${ }^{9} \mathrm{Em} O$ Cuidador de Gatos, filme de animação realizado sob a direção de Fernando Cortizo em 2008, a parte musical surge composta por Josh Rouse.

${ }^{10}$ O Apóstolo, filme de animação realizado sob a direção de Fernando Cortizo em 2010, possui uma componente musical composta por diversos autores: Philip Glass, Xavier Font e Aturo Vaquero. Inclui ainda alguns excertos de música popular espanhola. Este facto contribui para uma diversidade musical que se revela essencial no delinear do sonoro de uma obra tão particular como esta. Simultaneamente, surge constante o uso de diferentes efeitos sonoros que ilustram a narrativa do filme, construindo uma história onde o terror, o suspense e a emoção são constantes.

11 Sabemos que na realização de filmes comportando esta técnica, e nas animações propostas pelos autores, são produzidos e utilizados modelos em diversos materiais, sendo os mais comuns a massa de modelar e a plasticina. Conforme a técnica, e a necessidade, muitos desses modelos contêm sistemas de juntas mecânicos, com mecanismos de articulações muito complexos e realistas, conferindo realismo ao fixado em tela. No caso de realização de filmes mais extensos, o material utilizado tem de ser mais resistente e maleável. Os modelos são movimentados e fotografados quadro a quadro. Esses quadros são posteriormente montados numa película cinematográfica, criando a impressão de movimento. Nessa fase, podem ser acrescentados efeitos sonoros, como o discurso falado ou a música, o ruído, ou qualquer outro elemento que o autor ache pertinente utilizar para melhor ilustrar a sua intenção criativa.

12 Como exemplos salientamos o suspiro, a voz gutural, o sussurro, o grito. Se o grito está associado à vítima, a voz gutural encontra-se aliada ao agressor. Se o suspiro está relacionado com uma dimensão emotiva e afetiva do amor, o sussurro é relacionado a momentos de maior intimidade, mas também de mentira, de calunia, de manipulação. No caso do grito salientamos a sua importância enquanto representação sonora do sentimento de horror. O grito é o som seu definidor por excelência, sendo recorrente nos filmes deste género. Mencionar a importância do grito a nível sonoro não invalida o seu uso e importância na caracterização de personagens já no chamado filme mudo.
13 Neste sentido Mark Brownrigg (2003) realça o uso da música atonal como meio de enfatizar e propiciar estas emoções. Estas podem igualmente ser traduzidas através de técnicas de execução inovadora, ou pouco comum, dos instrumentos; alteração artificial do timbre dos mesmos através de manipulação eletrónica; fragmentação melódica acentuada, entre outras.

\section{Referências Bibliográficas}

Blanco, P. S. 2010. A potencialidade narrativa de uma "construção" sonoro-musical. Programa de Pós-graduação em Música. Escola de Música. Universidade Federal da Bahia. http://www2.ufba.br/ psotuyo/dir/artigos/Projeto $\% 20$ Musica\%20Narrativa.pdf. (acedido a 12 de maio de 2010).

Browrigg, M. 2003. Film Music and film Genre, Tese de Doutoramento, Universidade de Stirling.

Burt, G. 1994. The Art of Film Music. Boston: Northeastern University Press.

Chion, M. 1990. Audio-Vision: Sound on Screen. New York: Columbia University Press.

Cohen, A. J. 2001. "Music as a source of emotion in film". In:

Cook, N. 1998. Analyzing Musical Multimedia. Oxford: Oxford University Press.

Gorbman, Cl. 1987. Unheard Melodies: Narrative Film Music. Indianopolis: Indiana University Press.

Kracauer, S. 1997. Theory of Film: The Redemption of Physical Reality. New Jersey: Princeton University.

Langdale, A. (Org.) 2002. Hugo Münsterberg on Film. New York: Routledge.

Lipscomb, S. D. and Tolchinsky, D. E. 2005. The Role of Music Communication in cinema. Oxford: Oxford University Press.

Maheirie, K. 2003. Processo de criação no fazer musical: Uma objetivação da subjetividade, a partir dos trabalhos de Sartre e Vygotsky. Tese de Doutoramento Maringá. http:// www.scielo.br/pdf/pe/v8n2/v8n2a15.pdf. (acedido a 10 de fevereiro de 2010).

Wingstedt, J. (2016). Narrative Music: Towards an Understanding of Musical Narrative Functions in Multimedia. Sweden: School of Music, Luleå University of Technology. http://epubl.Itu.se/1402-1757/2005/59/. (Acedido a 23 de setembro de 2016). 